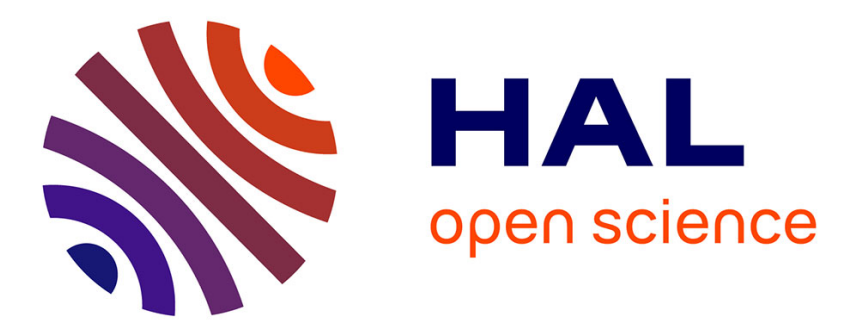

\title{
Product-process interface for manufacturing data management as a support for DFM and virtual manufacturing
}

Jawhar El Gueder, Florent Cochennec, Lionel Roucoules, Emmanuelle Rouhaud

\section{To cite this version:}

Jawhar El Gueder, Florent Cochennec, Lionel Roucoules, Emmanuelle Rouhaud. Product-process interface for manufacturing data management as a support for DFM and virtual manufacturing. International Journal on Interactive Design and Manufacturing, 2010, 4 (4), pp.251-258. 10.1007/s12008010-0109-1 . hal-00871110

\section{HAL Id: hal-00871110 https://hal.science/hal-00871110}

Submitted on 16 Oct 2013

HAL is a multi-disciplinary open access archive for the deposit and dissemination of scientific research documents, whether they are published or not. The documents may come from teaching and research institutions in France or abroad, or from public or private research centers.
L'archive ouverte pluridisciplinaire $\mathbf{H A L}$, est destinée au dépôt et à la diffusion de documents scientifiques de niveau recherche, publiés ou non, émanant des établissements d'enseignement et de recherche français ou étrangers, des laboratoires publics ou privés. 


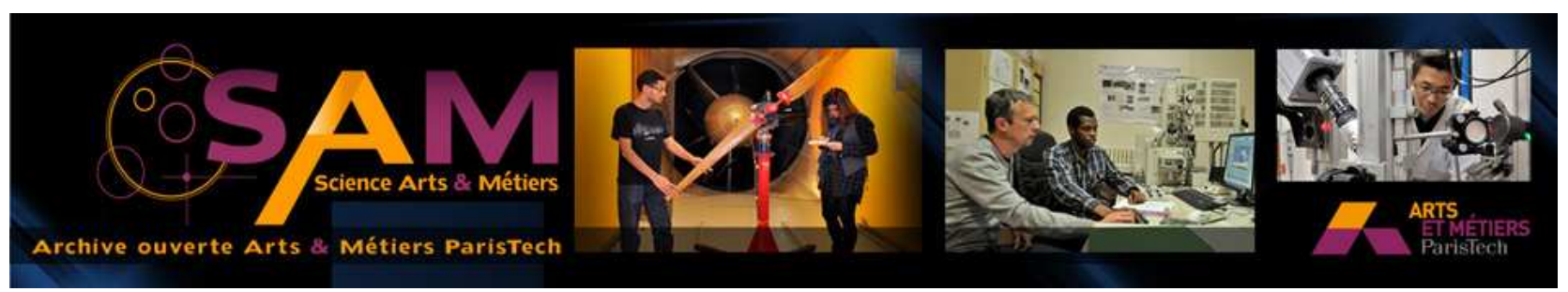

\section{Science Arts \& Métiers (SAM)}

is an open access repository that collects the work of Arts et Métiers ParisTech researchers and makes it freely available over the web where possible.

This is an author-deposited version published in: http://sam.ensam.eu

Handle ID: .http://hdl.handle.net/10985/7381

\section{To cite this version :}

Jawhar ELGUEDER, Florent COCHENNEC, Lionel ROUCOULES, Emmanuelle ROUHAUD -

Product-process interface for manufacturing data management as a support for DFM and virtual manufacturing - International Journal on Interactive Design and Manufacturing - Vol. 4, $\mathrm{n}^{\circ} 4$, p. $251-258-2010$ 


\title{
Product-process interface for manufacturing data management as a support for DFM and virtual manufacturing
}

\author{
Jawhar Elgueder • Florent Cochennec . \\ Lionel Roucoules • Emmanuelle Rouhaud
}

\begin{abstract}
In order to tackle a continuous improvement of virtual engineering, product modelling has to integrate more knowledge that refers to every decision taken during the product development process. Those decisions have to be related to the assessment of the whole product life cycle. This paper particularly addresses the domain of product's industrialisation that aims at selecting the manufacturing processes. This selection must currently be done as soon as possible and has to be strongly linked with product definition and computer aided design (CAD) modelling. This work first presents some new results concerning a product-process interface to integrate manufacturing information in the product model and how it leads to the definition of the CAD model. Then this interface that also manages specific information coming from the manufacturing process (tolerances, stresses gradient...) is used to improve the whole manufacturing process plan simulation. This process plan has, indeed, to track every material transformation issued from each manufacturing operation.
\end{abstract}

Keywords Product-process interface - DFM .

Virtual engineering - Manufacturing process selection . Manufacturing simulation

J. Elgueder · F. Cochennec $\cdot$ E. Rouhaud

Laboratory of Mechanical Systems and Concurrent Engineering, Charles Delaunay Institute, University of Technology of Troyes, FRE 2848, 12, rue Marie Curie, BP2060,

10010 Troyes Cedex, France

e-mail: jawhar.el_gueder@utt.fr

E. Rouhaud

e-mail: emmanuelle.rouhaud@utt.fr

L. Roucoules $(\square)$

Laboratory of Information Science and Systems, Arts et Métiers ParisTech, UMR 6168,

2, cours des Arts et Métiers, 13617 Aix en Provence, France

e-mail: lionel.roucoules@ensam.fr

\section{Introduction}

For almost 30 years computer aided design (CAD) systems have been developed and improved to currently reach very powerful features to support product's shape modelling. They are actually presented and used as one of the central systems that make the design process a geometric centric approach. This approach has shown its great interest in industry to tackle the problem of digitizing hand-done drawing, to improve the CAD-CAM (computer aided manufacturing) links and to enhance the process plan activity. Nowadays, the CAD model also finds an interest to improve the digital mockup used during a decision-making process. However current CAD systems are not able to manage all the information related to the product definition. This information as mentioned in [1] has to be related to the whole life cycle (from requirement specifications to dismantling information). The product, and its CAD model, is then defined, as far as possible, taken into account " $X$ " constraints as assumed in a DFX ${ }^{1}$ approach. One of the domains that have to be integrated in design is manufacturing (i.e. DFM). That means that manufacturing activities have to be assessed concurrently to the product development and the $\mathrm{CAD}$ modelling activities.

Once the CAD model done, manufacturing processes can be detailed. As far as manufacturing simulation is concerned, CAD model is seen as an input and software tools have to simulate the behaviour of the materials flow during each manufacturing operation (e.g. forging, casting, machining...).

The main issue of that design approach remains in the fact that:

\footnotetext{
${ }^{1}$ Design for $\mathrm{X}$ : design approach able to consider any activity information (e.g. manufacturing, assembly...), named " $X$ ", during the product development.
} 
- The CAD model is almost never defined considering manufacturing information.

- The manufacturing simulations do not take into account the history of the whole process plan. The input CAD is seen as virgin of any previous manufacturing operations.

This paper proposes new software tools to manage the whole manufacturing process plan information and to integrate these data (i.e. knowledge synthesis approach) in the product model. The CAD model can then be constructed interactively with respect to an adequate DFM approach. The tools have been developed in collaboration with industrial partners to attest the feasibility of their future implementation.

The second part introduces the design approach and the main concepts used to breakdown the product and its CAD model. It also gives the product-process interface concepts used to tackle the information synthesis.

The third part gives the first ideas and results to manage the manufacturing information of the global process in order to use it during the whole manufacturing simulation process.

Finally the conclusion and the perspectives for further work are enounced.

\section{Concepts of the DFM approach}

The fundamentals of DFM approach are the integration of manufacturing information ${ }^{2}$ constraints and data at the earliest stage of design. The model of integration, more precisely, the product-process interface model is based on concepts proposed by Roucoules and Skander [2]. They showed that the consideration of manufacturing information as soon as possible in the design process is of great interest for manufacturing process selection. This activity supports the emergence of product geometry [3] and tends to reduce the number of iterations between design and manufacturing decisions; the term of "right the first time" is used for such approaches versus the approaches of "do until right".

If the manufacturing domain is extended to life cycle phases (as assembly, recycling, dismantling, etc.), the design process should then be centred on multiple-views product modelling and expert analyses instead of being CAD centric. One of the main issues of CAD centric approaches remains in the unique product breakdown that does not reflect the design intends of every expert designers involved in the design group.

\footnotetext{
${ }^{2}$ Information is used in this work as both "new data" that complete product or process definition or "constraints" that is used to reduce the range of value of an existing data. Some details can be found in [3].
}

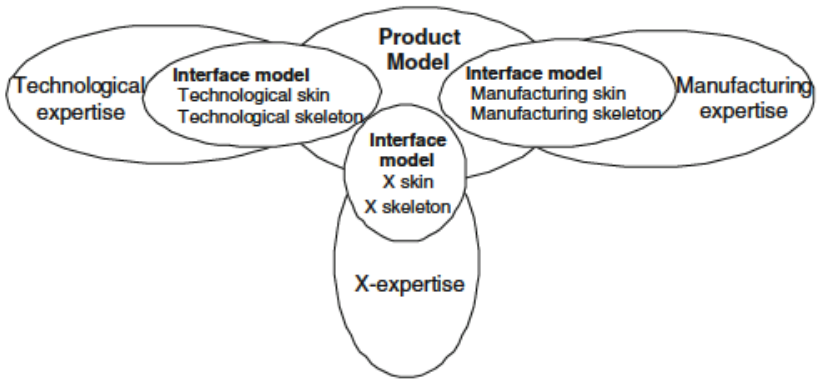

Fig. 1 Product modelling for " $\mathrm{X}$ " constraints integration

\subsection{Design context: CE, DFM and product modelling}

Integrated design aims at linking all mechanical expertises taking part in the design of a new product from functional specifications to the product's industrialisation and dismantling. Since this design concept appeared, many design methods, information management methods and models supporting the collaborative activities have been proposed $[4,5]$.

The general context of the work presented in this paper lies on the multiple views product breakdown concepts proposed in [6]. As presented in [7], the first design step consists in the definition of functional surfaces to achieve design requirements. These functional surfaces can emerge from a specific "Function-Structure" analysis that describes every product specifications as energetic flows in the product structure. One example based on FBS [8] and bond-graph concepts [9] is given in [10]. The second steps aims at integrating life cycle information to this product description. This approach is often called "design by least commitment".

Skander et al. [11] concentrate on the activity of "manufacturing process selection" ("manufacturing expertise" on Fig. 1) and then proposed to apply the Design For Manufacturing approach as soon as the first functional surface is defined. They thus propose a specific product model based on an adaptation of the skin and skeleton concepts $[12,13]$ to allow the " $X$ " constraints integration (see Fig. 1), and specifically the manufacturing constraints integration $[11,14]$.

This specific product model can be seen as an "interface model" used to specify the product information issued from different expertises (e.g. "technological components selection" or "manufacturing process selection"). These interface models that could also be called product-process interface are translated into a definition of the product with collaborative multiple views. The central "product modelling" concepts, and specifically the "relation" concept, are then used to link and/or propagate data from different expertises.

\subsection{Objectives of the DFM approach}

Once the first functional surfaces are specified, the design actor in charge of the industrialisation should wonder about 


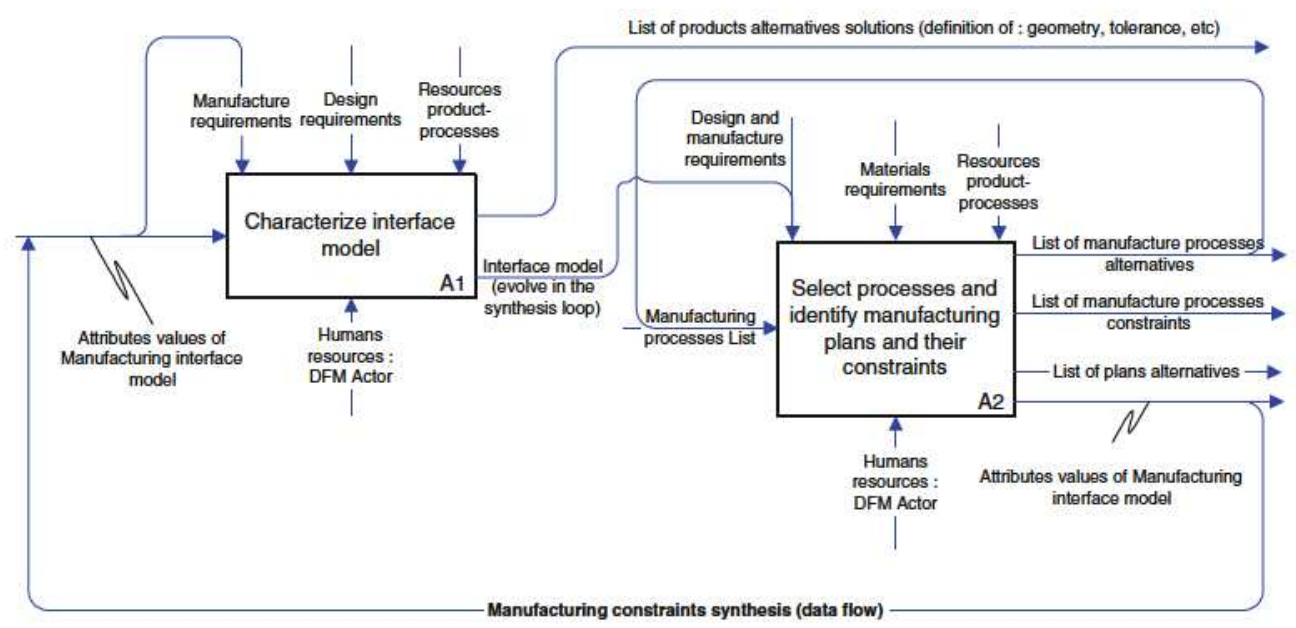

Fig. 2 The DFM activity schematization [2]

which manufacturing processes would be eligible for generating these surfaces. Many industrial and research studies have been done to characterise product-process relationships (e.g. [15]). Skander et al. proposed to translate these productprocess relationships in specific skin and skeleton attributes in order to analyse the correlation between product specifications and the process-resulting product characteristics. Then, the translation of the energetic flows definition in specific skin and skeleton attributes will lead to the creation of a technological interface model (see Fig. 1). Similarly the translation of the product-process relationships will lead to the creation of a manufacturing interface model corresponding to the product alternatives resulting from the analysis of all available manufacturing processes capabilities. Checking the consistency of the data contained in these two interface models will then imply the acceptance of some product-process alternatives and the reject of some others. The acceptance criteria are based on the fact that the data obtained during the product-process constraints identification must be sufficiently pertinent to define the process capabilities.

The DFM activity can be detailed as follows (cf. Fig. 2). The first task corresponds to the analysis of the requirements specification using energetic flows and specific technological interface model as presented on Fig. 1. Once this task achieved, the designer has to find product-process alternatives in which the manufacturing constraints are integrated. The DFM output is then a list of products with respect to available manufacturing plans. The selection of the final product-process alternatives is not treated in the presented approach. Indeed, such a choice is led by economic criterions and depends on many external factors as the factory production capabilities, the lead-time of the production.... The authors are nevertheless convinced that the proposition of product-process alternatives in which manufacturing constraints have been integrated brings solid arguments to the process selection activity.

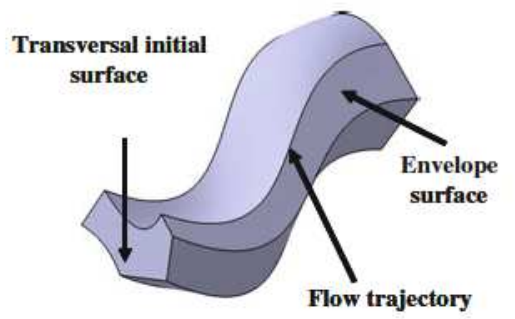

Fig. 3 Material flow definition for product-process interface

\section{Product-process interface proposal}

\subsection{Interface modelling}

As mentioned above the integration of manufacturing information is based on the proposed product-process interface presented in this section. That model comes from the assumption that every manufacturing operation is based on a material flow. Those flows (cf. Fig. 3) are then defined with:

- Sections defining the initial and final surfaces through which the material is going (i.e. transversal surfaces).

- A trajectory on which the material is formed.

- An envelope section that is generated.

Based on that flow (called manufacturing skeleton) the material can be added (e.g. injection), removed (e.g. machining) or deformed (e.g. forging) to obtain the final part surfaces (called manufacturing skin). Those surfaces are in the added and removed processes categories equal to the envelope surface.

Beyond very good results presented in [16] that concern the current results of that approach for nominal aspects, Fig. 7 gives the novelties of this paper. The new results concern the capabilities of that product-process interface: 


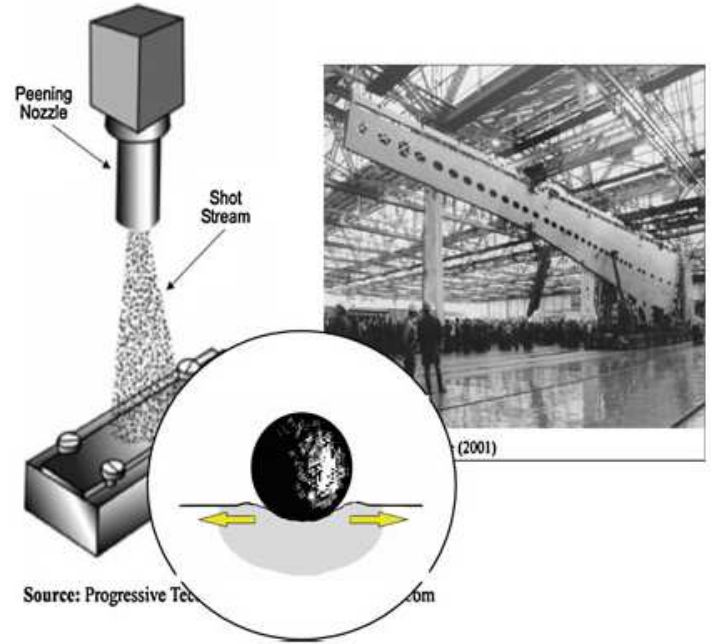

Fig. 4 Illustration of the peen-forming process

- To manage product tolerances coming from manufacturing operations. Each level of tolerancing features (dimensional tolerances, form tolerances and roughness) is concerned. Figure 7 shows how those features are integrated in the product-process interface characteristics.

- To manage material heterogeneities coming from manufacturing operations. Also material flows generate some gradients inside the manufactured product. Those gradients (called in the following "heterogeneities") can, for instance, come from (cf. Fig. 7):

- Thermal phenomena in the skeleton's sections that come from a cooling phase that is not always homogeneous during casting operations.

- Mechanical stresses gradient on the skeleton's trajectory due to past manufacturing processes and corresponding to residual stresses.

\subsection{Application of product-process interface to the peen-forming process}

The peen-forming process is developed as an example to present how these heterogeneities can be handled [17]. The peen-forming process is a cold-work-forming process mainly used in the aeronautical and aerospace industry to form large metallic panels (cf. Fig. 4). The concept is to project shots on the part in order to create local plastic deformation. The elastic equilibrium then generates sought global deformation of the panel.

The process presents many advantages: no spring-back problems are encountered; the parts can be formed at ambient temperature and the process induces little metallurgical modifications. The residual stress states are partially mastered and a good reproducibility can be achieved [18]. Being used for more than 50 years, this process is still under industrial and research development. Many analytical and numerical mod-

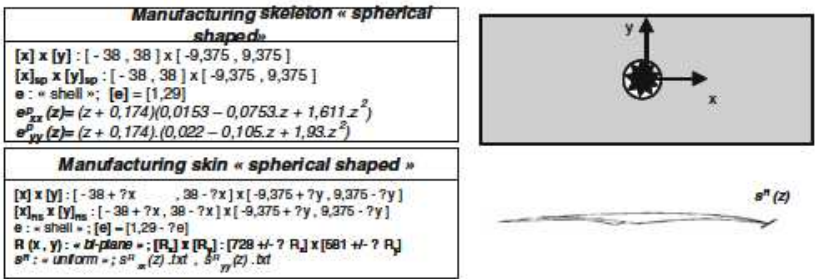

Fig. 5 Illustration of manufacturing skeleton concepts in a peen formed product case

els are proposed in the literature for predicting the geometrical distortions induced [19-22]. These models are based on the numerical introduction of equivalent plastic strains as an initial state of a finite element problem, which implies that the plastic strain fields induced by the treatment must be known. Some models have been proposed to predict the residual stress fields induced by known peening parameters [23] but these models are still to be developed in order to complete the state of knowledge of the process. These studies are indeed depending on the treated materials and on the peening parameters retained for the treatment. The actual state of knowledge makes thus difficult to plan the forming phases and trials and tests are still a needed way to achieve a specific geometry. This section treats the use of mechanical analysis to identify the product-process interface (i.e. material flow as presented in Sect. 3.1) as presented in [11] in order to integrate, as soon as possible, peen-forming information in the product definition following the general design approach presented in Sect. 2.2.

The peen-forming process specificity lies on the fact that the material flow induces an elastic response of the sheet blank which generates the global deformation. The forming origin is the incompatible plastic strain field induced by the shot impacts while the forming mechanism involved lies on the elastic strains resulting from the material compatibility condition. The authors decided as a first assumption to model the material flow taking into account the plastic strains induced by the treatment, these data being the starting point of the study of the induced deformation of the panel. Three basic curving attributes must be defined to cover the process capabilities: cylindrical, spherical and saddle shaped, the combination of these three attributes for the description of a large sheet metal being of course possible. Let us concentrate on the spherical form attribute, which is the simplest one. An illustration of a manufacturing skeleton and its corresponding manufacturing skin is given in Fig. 5 .

\subsection{Illustration of the product-process interface in the DFM approach}

With the classical CAD models kept in mind and considering the proposed product-process interface, the manufacturing product breakdown would be the following (cf. Fig. 6): 
Step 1

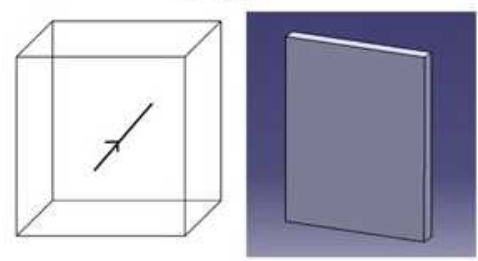

Step 2

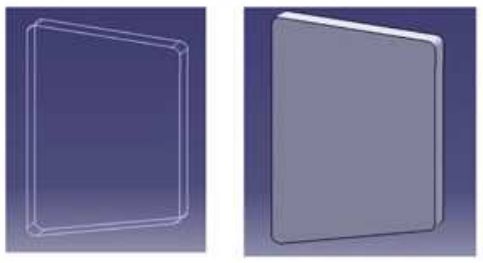

Step 3
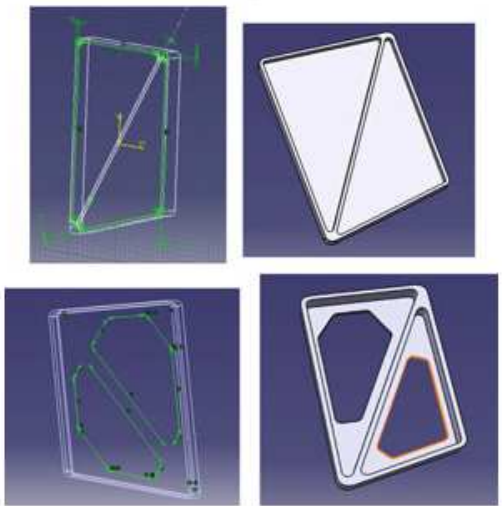

Fig. 6 Illustration of the proposed DFM approach

- An extrusion operation as primary process. Tolerances are integrated in the section of the extrusion skeleton (Step 1).

- A profiling machining operation as secondary process (Step 2).

- Four machining operations as secondary processes (Step 3).

The CAD model is then created according to manufacturing information (i.e. manufacturing skeleton) that leads the CAD breakdown and all the information related to product tolerances (as presented on Fig. 7).

\section{Managing manufacturing information for manufacturing process simulation}

So far we have presented how product-process interface is used in a DFM approach. The second goal is to take into account this new information of material heterogeneity (cf. Fig. 7) to better simulate each manufacturing operation. Every simulation can then, indeed, integrate an initial state

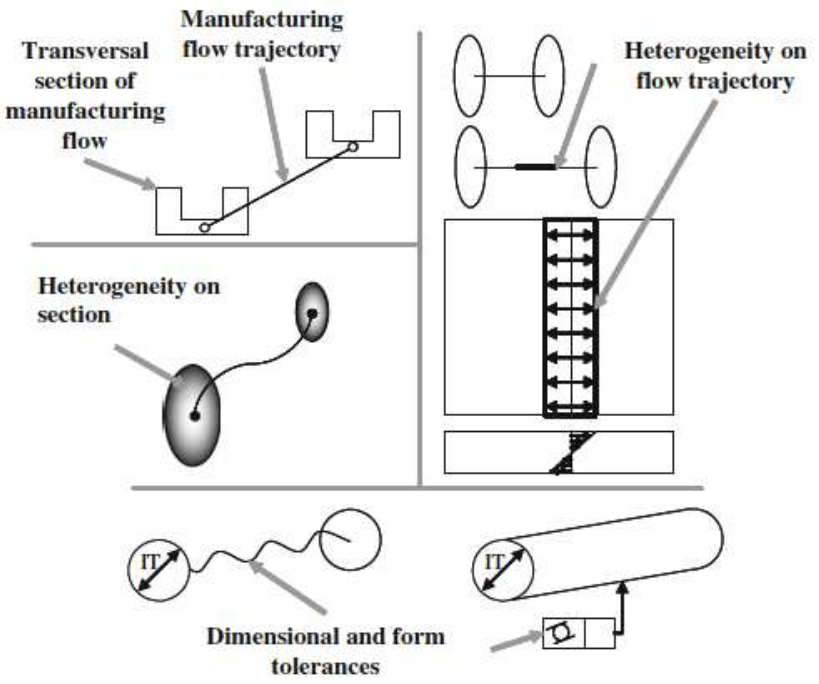

Fig. 7 Example of product information issued from manufacturing process and managed by the product-process interface

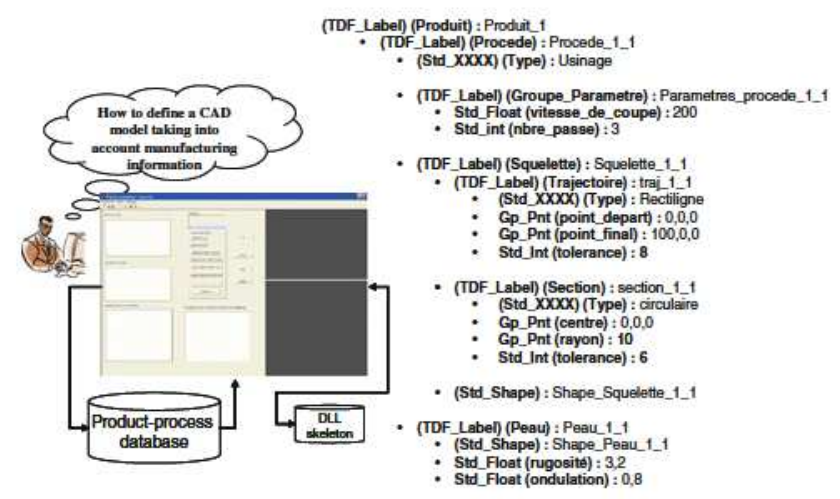

Fig. 8 Overview of the KBE application and product-process structure breakdown

with respect to the history of previous operations of the process plan. It is then necessary to model every gradient of information (e.g. stresses coming from forging, casting...) coming from this history.

\subsection{Manufacturing data management}

Figure 8 gives an overview of the $\mathrm{KBE}^{3}$ application developed to manage the global process plan with respect to the previously presented product-process interface.

That application proposes via its Graphic User Interface to manage both process and product information. The main functions of this interface give the possibility:

\footnotetext{
${ }^{3} \mathrm{KBE}:$ knowledge based engineering. Software developed in order to link CAD systems and Knowledge database.
} 
- To select the manufacturing process that could respect the requirements specification coming from the first step of the design approach.

- To define every manufacturing operation parameters. This is, so far, done manually by the user according to his experience and the expected final part.

- To define, via a database, product features based on manufacturing skeleton. That includes:

- The emergence of the product CAD model integrating all the manufacturing variability.

- The tolerances on the product coming from manufacturing capability.

- The product's material behaviour of the product (e.g. stresses gradient) coming from material flows.

The final structure breakdown therefore gives every product alternatives according to manufacturing process plan alternatives (cf. breakdown tree on Fig. 8) chosen by the user. It is important to note that each manufacturing alternative provides a $\mathrm{CAD}$ alternative and different material heterogeneity. The evolution of the CAD after each manufacturing operation with respect to that heterogeneity and to the simulation is then also different for each alternative. That why it is nowadays important to manage all the manufacturing information.

The data model of the KBE application is currently implemented using Open CASCADE Application Framework (OCAF) package encapsulated in Microsoft Foundation Components (MFC) objects and Open CASCADE 3D viewer.

\subsection{Manufacturing data management and simulation}

Based on this KBE application it is then possible to know what is the exact initial state of the product before each manufacturing operation simulation. This initial state obviously encapsulates the product behaviour issued from previous manufacturing operations. Indeed each manufacturing interface (i.e. manufacturing skeleton) of the data structure gives that information.

As presented in Fig. 9, the difficulty currently remains in transferring each gradient from the KBE data management structure to the initial model of the simulation (most often finite element simulation). Manufacturing skeletons are, indeed, not based on meshing and the gradient of information have then to be linked to topological parameters that have a strong meaning for manufacturing experts. That is not the case of any mesh that is only dedicated to specific simulation models.

Keeping the link between manufacturing parameters and product information is very useful to notify every change concerning product definition that can therefore be quickly
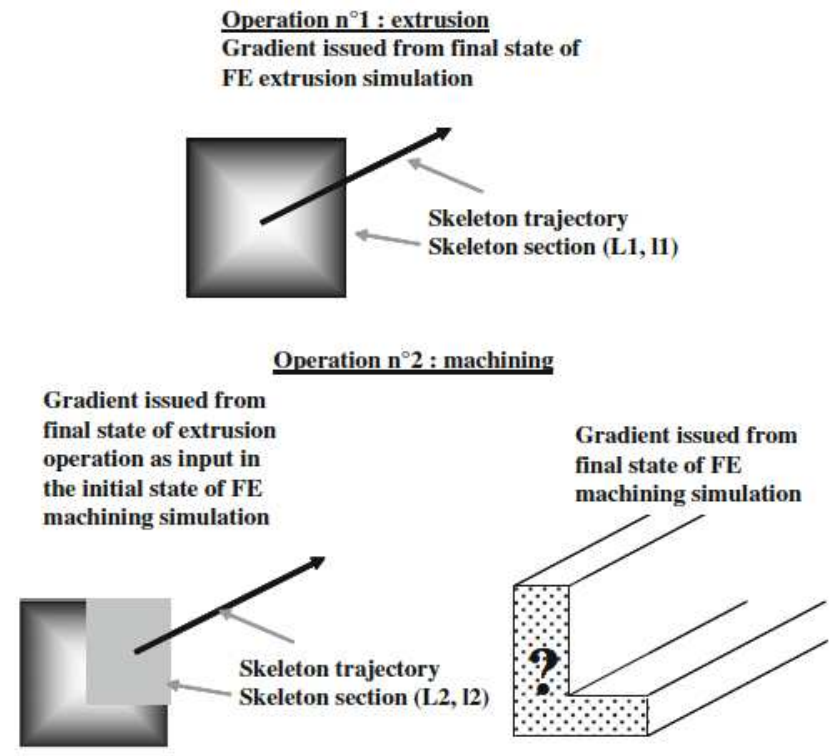

Fig. 9 KBE data management supporting field transfer for manufacturing simulation

propagated to manufacturing information without processing any new FEA.

The proposed solution is to link information gradients to each manufacturing skeleton that is represented by topological features and linked to manufacturing parameters (cf. Fig. 9). Each skeleton is adequate for each material flow of the given manufacturing operation. In very complicated cases for which information gradients cannot be explicit, a specific mesh could be associated to skeleton features; each mesh being also adequate to the specific material flow of the manufacturing operation.

\subsection{Illustration of manufacturing data management for manufacturing simulation}

Figure 10 illustrates how every product-process interfaces (i.e. manufacturing skeleton) are extracted from the KBE application to be used as input information in the FE simulation. This operation is detailed in this last part as an illustration of the possibilities of the proposed approach. The simulation is currently processed with ZSet as Finite Elements solver.

The first manufacturing operation (as given in Fig. 10) consists in extruding material. This creates the parallelepiped CAD model with attached tolerance and gradients as previously presented.

Figure 11 shows the global design process for each manufacturing operation using the KBE system. A manufacturing process database is used to guide the user choices and to complement the CAD systems by adding the engineering knowledge that drives the product process design 


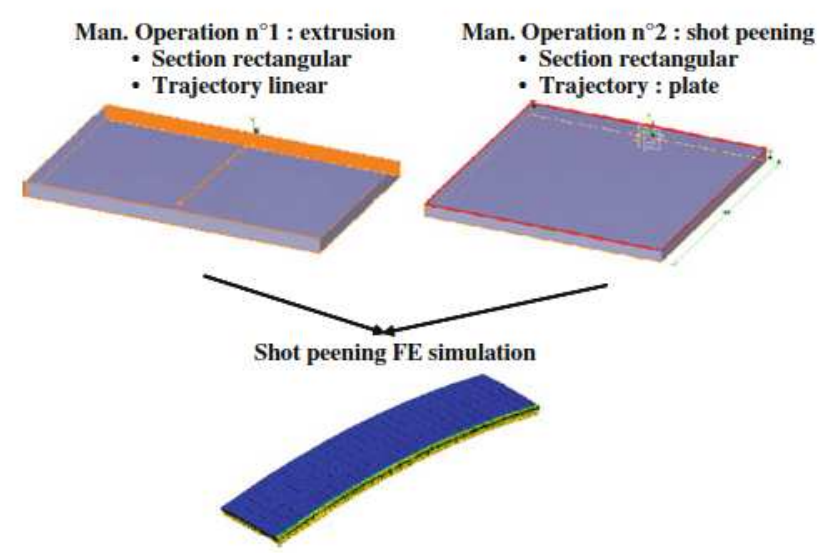

Fig. 10 Illustration of manufacturing simulation with respect to manufacturing skeleton features

[24]. Experimental relations, physical equations and manufacturing rules are stored in the database, to be used as relations linking process parameters to product parameters.

The proposed example is centered on the integration of residual stresses induced by manufacturing operations and how these stresses affect the final geometry. This justify the use of finite element calculation (Step 5 in Fig. 11) to obtain the deformed geometry, one important feature of the enhanced CAD model. The CAD model is automatically created using adequate $\mathrm{OCC}$ algorithms that instantiate productprocess interface attributes: section, trajectory....

Figure 12 gives more details about how the FE simulation is used. The case of peen-forming is again treated here (corresponding to the second manufacturing operation in Fig. 10). The shots impact the upper face of the part and this generates plastic deformations as presented in Sect. 3.2.

Manufacturing information (the peen-forming parameters, the part material, and the impacted surface) is extracted of the DFM software and is exchanged, via text files, to the ZSet solver.

This simulation of the peen-forming operation provides the curved part presented on Fig. 12. The final residual stress gradient is integrated in the manufacturing interface model to be used for potential further manufacturing operations. Finally, once the entire manufacturing process plan is defined and the respective product information (form + tolerancing + residual stresses field + etc...$)$ is generated, all this information could be exchanged with fatigue analysis tools.

\section{Conclusion and recommendations for future work}

This paper presents a product-process interface model for design for manufacturing (DFM) approach. This model based

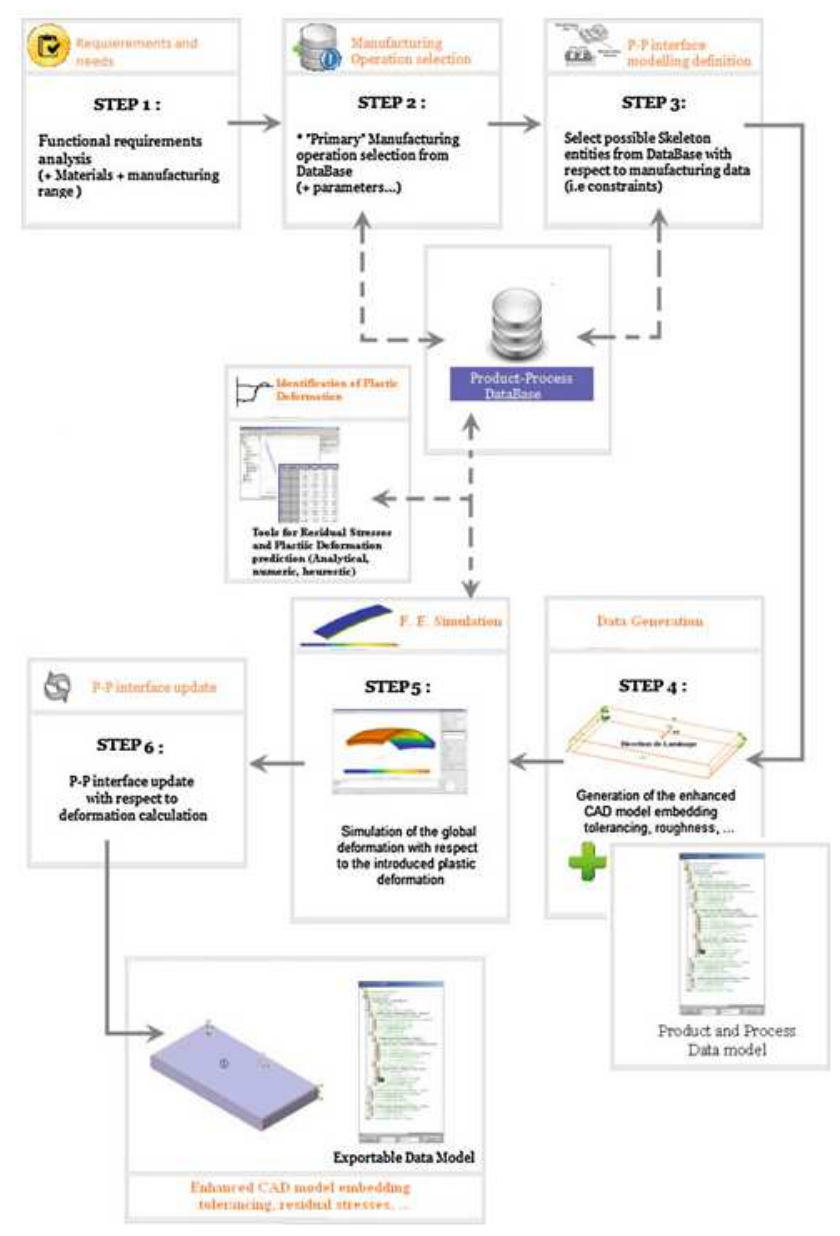

Fig. 11 Overview of the global design process using the KBE system

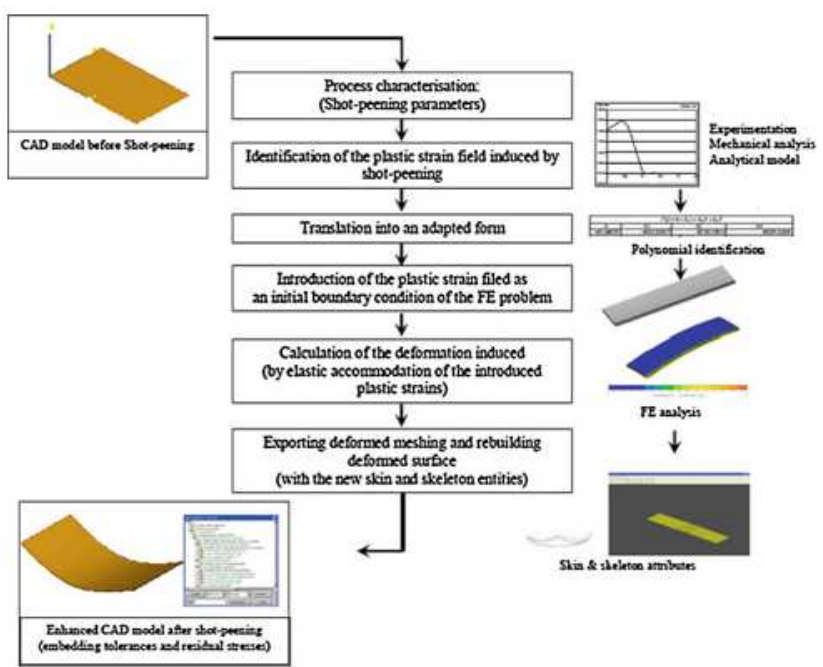

Fig. 12 Illustration of FE simulation for the calculation of the deformed part due to residual stress introduced by shot-peening

on material flow modelling with respect to skeleton and skin concepts is first used to integrate manufacturing information as soon as possible in the product design process (i.e. "by least commitments design approach"). This integration 
strongly leads the CAD modelling and by the way focuses the design process on expert designers' knowledge and not on CAD model any more.

The second objective of that interface model is to manage manufacturing information linked to product characteristics (e.g. topology, tolerances, material behaviour...). It is then easy to use that link to simulate manufacturing processes taking into account the evolution of product characteristics with respect to the manufacturing plan. The whole history of each manufacturing operation is then linked to the product definition that is not currently the case in CAD centric design approach.

The main perspectives for future work concern:

- The achievement of the KBE application in order to test more complicated cases. The current developments are related to the implementation of a skeleton library and the coupling with a product-process database.

- The implementation of field transfer mechanisms to support the whole management of the manufacturing process simulation.

Acknowledgment This research work was supported by SNECMA as part of the MAIA (http://www.le-webmag.com/article.php3?id_ article $=2$ \&lang $=$ ) project, the Region Champagne-Ardennes and Sisson Lehmann of the Wheelabrator group.

\section{References}

1. Krause, F.-L., Kimura, F., et al.: Product modelling. Ann. CIRP 42(2), 695-706 (1993)

2. Roucoules, L., Skander, A.: Manufacturing process selection and integration in product design. Analysis and synthesis approaches. In: Proceedings of the CIRP Design Seminar, Grenoble (2003)

3. Roucoules, L., Lafon, P. et al.: Knowledge intensive approach towards multiple product modelling and geometry emergence to foster cooperative design. In: Proceedings of the CIRP Design Seminar, Kananaskis (2006)

4. Sohlenius, G.: Concurrent Engineering. Ann. CIRP 41(2), 645655 (1992)

5. Andreasen, M., Hein, L.: Integrated Product Development. Springer, London (1987)

6. Tichkiewitch, S.: Specifications on integrated design methodology using a multi-view product model. In: Proceedings of the ASME Engineering Systems Design and Analysis Conference, Montpellier (1996)
7. Roucoules, L., Tichkiewitch, S.: CoDE: a co-operative design environment. A new generation of CAD systems. CERA 8(4), 263$280(2000)$

8. Gero, J.S.: Design Prototypes: a Knowledge Representation Schema for Design. AI Magazine, vol. 11, issue 4, pp. 26-36(1990)

9. Thoma, J.: Introduction to Bondgraphs and Their Application. Pergamon Press, Oxford (1975)

10. Klein Meyer, J.S., Roucoules, L., De Grave, A., Chaput, J.: Case study of a MEMS switch supported by a FBS and DFM framework. In: Proceedings of the 17th CIRP Design Conference, Berlin. ISBN 978-3-540-69819-7 (2007)

11. Skander, A.: Méthode et modèle DFM pour le choix des procédés et l'intégration des contraintes de fabrication vers l'émergence de la solution produit. PhD thesis, UTT, Troyes (2006)

12. Wu, M.-C., Wu, T.Y.: A skeleton approach for modelling assembly products. J. Des. Manuf. 3, 121-133 (1993)

13. Tollenaere, M., Belloy, Ph., Tichkiewitch, S.: A part description model for the preliminary design. In: Soenen, R. (ed.) Advanced CAD/CAM Systems, State-of-the-art and Future Trends in Feature Technology, pp. 129-143. Chapman \& Hall, London (1995)

14. Roucoules, L.: Méthodes et connaissances : contribution au développement d'un environnement de conception intégrée. $\mathrm{PhD}$ thesis, INPG, Grenoble (1999)

15. Boothroyd, G., et al.: Product Design for Manufacture and Assembly. Marcel Dekker, New York. ISBN 0-82479-176-2 (1994)

16. Skander, A., Roucoules, L., Klein Meyer, J.S.: Design and manufacturing interface modelling for manufacturing processes selection and knowledge synthesis in design. Int. J. Adv. Manuf. Technol. 37, 443-454 (2008)

17. Cochennec, F., Roucoules, L., Rouhaud, E.: Mechanical analysis to identify knowledge for a DFM approach. Application to shot peenforming process. In: Proceedings of Virtual Concept 2006 Conference, Playa Del Carmen, Mexico, 26 Nov-1 Dec 2006 (2006)

18. Ramati, S., Kennerknecht, S., et al.: Single piece wing skin utilization via advanced peen forming technologies. In: Proceedings of the ICSP7, Warsaw (1999)

19. Guagliano, M.: Relating Almen intensity to residual stresses induced by shot-peening: a numerical approach. J. Mater. Process. Technol. 110, 267-286 (2001)

20. Grasty, L.V., Andrew, C.: Shot peen forming sheet metal: finite element prediction of deformed shape. J. Eng. Manuf. 210, 361365 (1996)

21. Homer, S.E., VanLuchene, R.D.: Aircaft wing skin contouring by shot-peening. J. Mater. Shap. Technol. 9(2), 89-101 (1991)

22. Han, K., Owen, D.R.J., et al.: Combined finite/discrete element and explicit/implicit simulations of peen forming process. Eng. Comput. 19(1), 92-118 (2002)

23. Rouhaud, E., Deslaef, D., et al.: Handbook on Residual Stress. Society for Experimental Mechanics, USA (2005)

24. Dantan, J.Y., Hassan, A., Etienne, A., Siadat, A., Martin, P.: Information modeling for variation management during the product and manufacturing process design. Int. J. Interact. Des. Manuf. 2, 107. doi: $10.1007 / \mathrm{s} 12008-008-0040-\mathrm{x}$ 